\title{
«BSE-Gentest»: Geschäft mit der Angst
}

Schweizerische Akademie der Medizinischen Wissenschaften

Eine Gruppe von Zürcher Privatlaboratorien bietet einen Gentest an, welcher beim Menschen den individuellen «DNA-Bauplan in Bezug auf das BSE-Risiko» bestimmen soll. Nach Ansicht der Schweizerischen Akademie der Medizinischen Wissenschaften ist dieser Fr. 250.- teure Test nutzlos und zielt lediglich darauf ab, mit der Angst der Bevölkerung vor BSE Geschäfte zu machen.

Korrespondenz: Generalsekretariat der SAMW Petersplatz 13

CH-4051 Basel

Tel. 0612699030

E-Mail: mail@samw.ch
Seit einiger Zeit besteht Gewissheit darüber, dass BSE («Rinderwahnsinn») durch den Verzehr von infiziertem Rindfleisch auch auf den Menschen übertragen werden kann. Bisher erkrankten in Grossbritannien rund 100 Menschen an der sogenannten variant-Creutzfeld-Jakob-Krankheit (vCJD). Auffälligerweise wiesen die an vCJD erkrankten Menschen alle ein bestimmtes genetisches Muster auf - allerdings besitzen 40\% der Bevölkerung dieses Muster. Diese Beobachtung möchte nun eine Gruppe von Zürcher Privatlaboratorien zu Geld machen: In öffentlich aufgelegten Prospekten werben sie für einen Gentest, mit dem eine solche individuelle «Neigung» zur Entwicklung von vCJD festgestellt bzw. ausgeschlossen werden soll. Dieser Gentest kostet Fr. 250.- und wird von den Krankenkassen nicht vergütet.
Dieser Test ist aus zwei Gründen abzulehnen:

1. Der Test ist völlig nutzlos: Ein negatives Ergebnis («keine Neigung») kann eine mögliche spätere Erkrankung an CJD nicht völlig ausschliessen, aber das Risikobewusstsein vermindern; ein positiver Befund («es besteht eine Neigung») hat - da die Ansteckungsrate zumindest nach bisherigen Erkenntnissen sehr klein ist - in den meisten Fällen unnötigerweise Angst und Verunsicherung zur Folge. Ausserdem besteht zum jetzigen Zeitpunkt für tatsächlich erkrankte Personen keine Behandlungsmöglichkeit.

2. Die Durchführung eines genetischen Tests ohne gleichzeitige Beratung ist unseriös und kann - unter anderem aus den eben beschriebenen Gründen - mehr Schaden als Nutzen anrichten.

Die Schweizerische Akademie der Medizinischen Wissenschaften (SAMW) verurteilt das Vorgehen dieser Laboratorien: Es zielt darauf ab, mit der Angst der Bevölkerung vor BSE Geschäfte zu machen. Die SAMW bedauert, dass wissenschaftlich beratene Laboratorien mit dieser Vorgehensweise die Ernsthaftigkeit der Wissenschaft in Frage stellen und ihren Ruf in der Öffentlichkeit aufs Spiel setzen. 